\title{
Tratamento de resíduos sólidos de centrais de abastecimento e feiras livres em reator anaeróbio de batelada
}

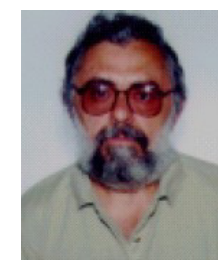

\author{
Valderi D. Leite ${ }^{1}$, José T. de Sousa ${ }^{1}$, Shiva Prasad ${ }^{2}$, Wilton S. Lopes ${ }^{1}$, \\ Gilson B. Athayde Júnior ${ }^{1} \&$ Alberto M. M. Dantas ${ }^{1}$
}

\begin{abstract}
1 DQ/CCT/UEPB. Av. Vig. Calixto 1475, CEP 58104-485, Campina Grande, PB. Fone: (83) 337-2793. E-mail: valderi@paqtc.rpp.br (Foto)
2 DEQ/CCT/UFCG, CEP 58109-970, Campina Grande, PB. Fone: (83) 333-3171
\end{abstract}

Protocolo $40-2 / 4 / 2002$ - Aprovado em 30/5/2003

\begin{abstract}
Resumo: Em feiras livres e centrais de abastecimento são produzidas quantidades bastante significativas de resíduos sólidos, com características favoráveis ao aproveitamento integral em processo de bioestabilização anaeróbia. $O$ processo de bioestabilização é realizado em reatores anaeróbios de batelada (RAB), com tempo de detenção de sólidos variando de 250 a 300 dias originando, como produtos finais, o biogás, com cerca de $60 \%$ de gás metano, além de composto orgânico parcialmente bioestabilizado. Neste trabalho, foram utilizados resíduos sólidos orgânicos tipicamente vegetais, advindos de centrais de abastecimento, feiras livres e lodo de esgoto sanitário. O sistema experimental utilizado era constituído basicamente por um reator anaeróbio de batelada, com capacidade unitária de 2200 litros, além de outros dispositivos complementares. O sistema experimental foi instalado e monitorado na Estação Experimental de Tratamento Biológico de Esgoto Sanitário, situada no Bairro do Tambor, na cidade de Campina Grande, Estado da Paraíba, no período de janeiro a setembro de 2001. No processo de monitoração foram realizadas caracterizações sistemáticas das frações sólidas, líquidas e gasosas. Após análise dos dados, ficou evidenciada a viabilidade desta alternativa de tratamento, restando ser investigada ainda a viabilidade econômica, quando comparada com outras alternativas tecnológicas de tratamento de resíduos sólidos orgânicos.
\end{abstract}

Palavras-chave: anaeróbio, reator de batelada, resíduos sólidos, biogás, lodo

\section{Treatment of solid waste from supply centers and free markets in batch anaerobic reactor}

\begin{abstract}
Significant quantity of organic solid waste with favorable characteristics for integral utilization in anaerobic biostabilization is produced in free markets and supply centers. The process is conducted in anaerobic batch reactors (ABR), with detention time of solids varying from 250 to 300 days, producing biogas with about $60 \%$ of methane, besides the partially biostabilized organic compost as the final product. In this study, the organic solid waste used was typically of vegetables, originated from the supply centers, free markets and sanitary wastewater sludge. The experimental system used was basically constituted of a batch anaerobic reactor of 2200 L capacity, besides the other complementary devices. The experimental system was installed and monitored during the period of January to September 2001 at the Experimental Station for Biological Treatment of Sanitary Sewage, located at Tambor, Campina Grande, in the State of Paraíba, Brazil. During the process of monitoring the systematic characterization of the solid, liquid and gaseous fractions were realized. After analyzing the data, the feasibility of this alternative treatment, was evidenced although the economic viability in comparison to other technological alternatives of treatment of organic solid waste remains to be tested.
\end{abstract}

Key words: anaerobic, batch reactor, solid waste, biogas, sludge

\section{INTRODUÇÃO}

O acelerado avanço tecnológico, associado a um intenso processo de urbanização, tem causado sérios problemas ambientais ao planeta, sobretudo nas nações menos desenvolvidas ou em estágio de desenvolvimento. As agressões ambientais são devidas, basicamente, à exploração predatória dos recursos naturais e à falta de medidas balizadoras para o controle do lançamento de resíduos sólidos, líquidos e gasosos. No caso específico do Brasil assiste-se, diuturnamente, nos mais diversificados meios de comunicação, serem anunciados diversos tipos de agressões ambientais, causadas pelo setor privado e também pela máquina estatal.

Segundo IPT (2000), no Brasil são produzidas em torno de 100 mil toneladas de resíduos sólidos domiciliares por dia. Os resíduos sólidos domiciliares representam fração bastante 
significativa dos resíduos sólidos urbanos e são constituídos, basicamente, por materiais orgânicos fermentáveis, podendo ser aproveitados em processo de bioestabilização aeróbio ou anaeróbio. Quanto aos resíduos sólidos urbanos, são constituídos, em geral, por resíduos sólidos domiciliares, papel e papelão, trapos, palhas, folhagens e tecidos celulares, considerados materiais celulósicos e se enquadram dentre os compostos químicos denominados carboidratos (Tchobano-glous et al., 1993). Os dados oficiais do Brasil demonstram que do total de resíduos sólidos urbanos coletados, apenas 30\% vêm recebendo algum tipo de tratamento, enquanto os $70 \%$ restantes são lançados em lixões, causando sérios impactos ambientais. Dentre os impactos causados pelo lançamento inadequado de resíduos sólidos urbanos, citam-se várias doenças, tais como a salmonelose, a hepatite, a febre tifóide e paratifóide, a leptospirose, dentre outras, contraídas pelo contato direto com os resíduos ou por contato indireto, via macro e micro vetores.

Os processos anaeróbios remontam ao povo romano e, desde então, têm sido utilizados para diversos fins, principalmente para tratar resíduos que apresentem elevada carga orgânica. Em princípio, todos os resíduos sólidos orgânicos, quer sejam de origem animal ou vegetal, podem ser bioestabilizados anaerobiamente.

No Brasil, o processo anaeróbio tem sido utilizado para bioestabilizar lodo de esgoto sanitário e efluentes líquidos com elevada demanda bioquímica de oxigênio e, em alguns casos específicos, resíduos sólidos de origem rural.

Segundo Barlaz \& Ham (1989), o processo de bioestabilização anaeróbia de resíduos sólidos orgânicos obedece às mesmas vias metabólicas já estabelecidas para bioestabilização anaeróbia de lodo.

O metabolismo bacteriano compreende a utilização pelas bactérias do material orgânico como fonte de energia para as diversas atividades inerentes à realização do processo (van Haandel \& Lettinga, 1994). No geral, o processo de bioestabilização anaeróbia tem início quando os sólidos suspensos voláteis alimentados ao sistema são hidrolisados, produzindo demanda química de oxigênio (DQO) solúvel. A DQO solúvel serve de alimento às bactérias e, por conseguinte, à síntese celular, dando origem a uma biomassa microbiana relativamente densa. Em condições de respiração endógena, parte da biomassa, por lise das células, volta a produzir DQO solúvel, sendo que o restante forma uma massa inerte. A biomassa formada quando sobre condições de respiração endógena, parte das células lisadas se transforma novamente em DQO solúvel e o restante forma uma massa inerte (Pavlostathis, 1988).

Objetivou-se, neste trabalho, estudar a viabilidade do emprego de reator anaeróbio de batelada para o tratamento de resíduos sólidos vegetais e lodo de esgoto sanitário, com concentração de sólidos totais em torno de $20 \%$ (base) além da determinação da taxa de produção de gás metano.

\section{MATERIAL E MÉTODOS}

O sistema experimental para realização deste trabalho foi instalado e monitorado na Estação Experimental de Tratamento Biológico de Esgoto Sanitário (EXTRABES), localizada no
Bairro do Tambor, na cidade de Campina Grande, PB. O reator anaeróbio de batelada utilizado foi construído à base de fibra de vidro, com capacidade unitária de 2200 L. No reator foram instalados dispositivos para a coleta de percolado e de biogás, além de um distribuidor superficial de água na massa de resíduo. Para carregamento do reator utilizaram-se resíduos sólidos vegetais advindos de central de abastecimento e feira livre (RSV) e lodo de estação de tratamento de esgotos sanitários (LES). Após coletados, os resíduos sólidos vegetais foram transportados para o laboratório e submetidos ao processo de trituração. Em seguida realizou-se a determinação do percentual de umidade dos resíduos sólidos vegetais e do lodo de esgoto sanitário. Conhecendo-se o percentual de umidade dos RSV e do LES, procedeu-se à preparação do substrato, que no caso específico deste trabalho, foi constituído por $80 \%$ de RSV mais $20 \%$ de LES (percentagem em peso). A carga orgânica aplicada foi de $600 \mathrm{~kg}$ de substrato $\mathrm{m}^{-3}$ reator, com período de detenção de sólidos de 270 dias.

Na Figura 1 apresentam-se o protótipo do reator anaeróbio de batelada e os diversos dispositivos complementares, constituintes do sistema experimental

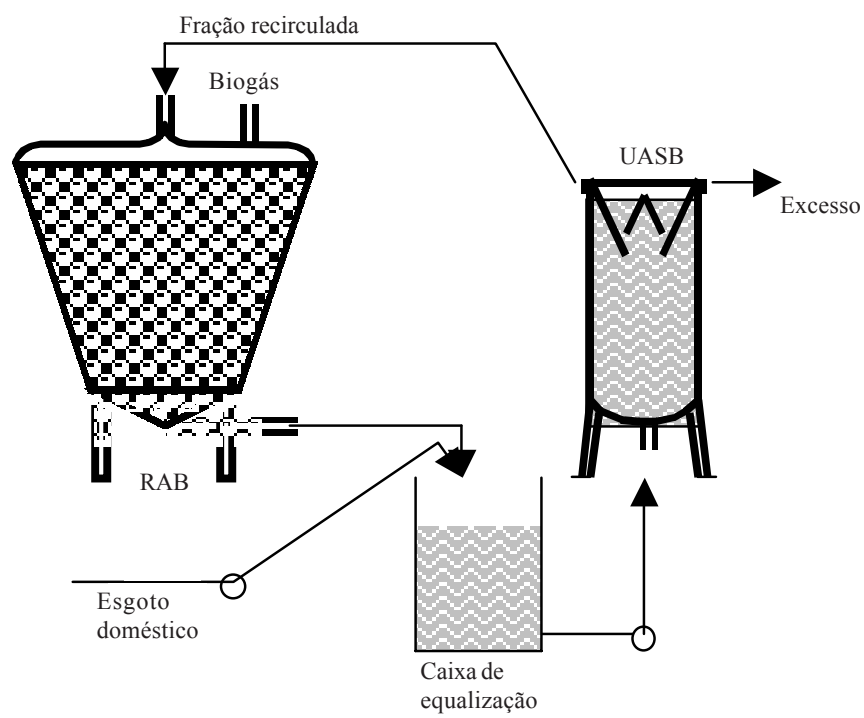

Figura 1. Unidades constituintes do sistema experimental

Na Tabela 1 são apresentados os principais parâmetros operacionais do reator anaeróbio de batelada (RAB).

Tabela 1. Parâmetros operacionais

\begin{tabular}{ccccccc}
\hline $\begin{array}{c}\mathrm{V}_{\text {Reator }} \\
(\mathrm{L})\end{array}$ & $\begin{array}{c}\mathrm{M}_{\mathrm{RSV}} \\
(\mathrm{kg})\end{array}$ & $\begin{array}{c}\mathrm{M}_{\mathrm{LES}} \\
(\mathrm{kg})\end{array}$ & $\begin{array}{c}\mathrm{TU} \\
(\%)\end{array}$ & $\begin{array}{c}\mathrm{TOP} \\
(\mathrm{dias})\end{array}$ & $\begin{array}{c}\text { Prop. RSV/LES } \\
(\%)\end{array}$ & $\begin{array}{c}\mathrm{M}_{\text {DQO }} \\
(\mathrm{kg})\end{array}$ \\
\hline 2200 & 1057,6 & 264,4 & 80 & 270 & $80 / 20$ & 114,3 \\
\hline
\end{tabular}

RSV - Resíduos sólidos vegetais; TU - Teor de umidade; TOP - Tempo de operação; LES - Lado de esgoto sanitário; DQO - Demanda química de oxigênio

O acompanhamento do desempenho do processo de bioestabilização foi realizado através da quantificação de parâmetros analíticos nas frações líquidas e gasosas. Na fração líquida as amostras foram coletadas com freqüência quinzenal e submetidas às seguintes análises: $\mathrm{pH}$, sólidos totais voláteis (STV), demanda química de oxigênio (DQO), nitrogênio total Kejdahl (NTK), nitrogênio amoniacal $\left(\mathrm{N}^{-\mathrm{NH}_{4}}{ }^{+}\right)$, fósforo total (PT) e 
carbono orgânico total (COT). Na fração gasosa, o monitoramento consistia na medida diária do fluxo de biogás produzido e, em dias alternados, realizava-se a análise da composição volumétrica do biogás. Para a realização das análises físicas e químicas utilizou-se o método preconizado por APHA (1995). Após o período de 270 dias de monitoração, o reator foi retirado de operação e o resíduo remanescente e parcialmente bioestabilizado foi submetido à caracterização física e química.

\section{RESULTADOS E DISCUSSÃO}

O substrato utilizado neste trabalho era formado, basicamente, por $80 \%$ (percentagem em peso) de resíduos sólidos vegetais, mais $20 \%$ (percentagem em peso) de lodo de esgoto sanitário. A utilização deste tipo de substrato se justifica pela perda significativa de restos de frutas e verduras que acontece nas centrais de abastecimento, feiras livres e residências, em todo o território nacional, e pela escassez de sistemas de tratamento para os lodos de esgotos sanitários gerados nas estações de tratamento de esgotos sanitários (ETES) existentes. $\mathrm{Na}$ Tabela 2 são apresentados os principais parâmetros físicos e químicos dos resíduos sólidos vegetais e do lodo de esgoto sanitário utilizado para a preparação do substrato.

Tabela 2. Parâmetros físicos e químicos dos RSV e do LES utilizados na preparação do substrato

\begin{tabular}{ccccccccc}
\hline $\begin{array}{c}\text { Parâmetros } \\
\text { Resíduos }\end{array}$ & $\mathrm{pH}$ & $\mathrm{TU}$ & $\mathrm{ST}$ & $\mathrm{STV}$ & DQO & NTK & PT & COT \\
\cline { 3 - 8 } & & \multicolumn{7}{c}{$(\%)$} \\
RSV $^{(*)}$ & 4,6 & 77,1 & 22,9 & 83,6 & 43,2 & 2,8 & 0,40 & 46,2 \\
LESS $^{(* *)}$ & 7,5 & 80,0 & 20,0 & 46,5 & 29,8 & 1,3 & - & 25,8 \\
\hline
\end{tabular}

* Resíduos sólidos vegetais.

** Lodo de esgoto sanitário

TU - Teor de umidade; ST - Sólidos totais; STV - Sólidos totais voláteis; DQO - Demanda química de oxigênio; NTK - Nitrogênio total kjedahl; PT - Fósforo total; COT - Carbono orgânico total

Os resíduos sólidos vegetais apresentaram, na época da coleta, características ligeiramente ácidas, elevado percentual de umidade e sólidos totais voláteis. Os teores de COT, NTK e PT apresentaram-se próximos aos teoricamente recomendados para o processo de digestão anaeróbia, o que nem sempre acontece quando se trata de resíduos sólidos urbanos.

Realizada a caracterização física e química dos resíduos sólidos vegetais e do lodo de esgoto sanitário, procedeu-se à preparação do substrato sendo, em seguida, alimentado o reator. A massa total de substrato aplicada ao reator foi de $1322,0 \mathrm{~kg}$, o que corresponde a 1057,60 kg de resíduos sólidos vegetais, e 264,40 kg de lodo de esgoto sanitário, em base úmida. Como o percentual de umidade do substrato era de $80 \%$, em base seca tinha-se apenas $264,4 \mathrm{~kg}$ de sólidos totais, com uma massa de STV e DQO de 221,03 e 114,2 kg, respectivamente. Da massa total de substrato alimento ao reator, pode-se observar que $80 \%$ (percentagem em peso) correspondiam à massa de água em suas diferentes formas. A presença da água na massa de substrato favorece a aceleração das diferentes taxas de bioestabilização, contribuindo para a redução do tempo necessário para que grande parte do material orgânico seja bioconvertido em produtos finais.
Para o acompanhamento do desempenho do processo de bioestabilização anaeróbia do substrato, realizava-se coleta e análise de diversos parâmetros em amostras da fração líquida, além da quantificação e qualificação da fração gasosa. Na fração líquida denominada, neste trabalho, percolado, que é o resultado das diversas frações de água presente no substrato, somada à água advinda das reações enzimáticas naturais do próprio processo, a coleta foi realizada com freqüência quinzenal e submetida a análise para determinação de parâmetros físicos e químicos.

$\mathrm{O} \mathrm{pH}$ expressa, de forma geral, a presença, no percolado, de espécies químicas de natureza ácida ou alcalina. Neste tipo de processo, a hidrólise bioquímica dos resíduos sólidos orgânicos gera ácidos orgânicos do tipo propionato, valerato, isovalerato, butirato etc; portanto, a quantificação rotineira do pH expressa, geralmente, a concentração de espécies ácidas ou alcalinas, contribuindo para que se possa ter uma avaliação preliminar do desempenho do processo. Na Figura 2 apresentase o perfil do $\mathrm{pH}$ nos líquidos percolados durante o período de monitoração do reator.

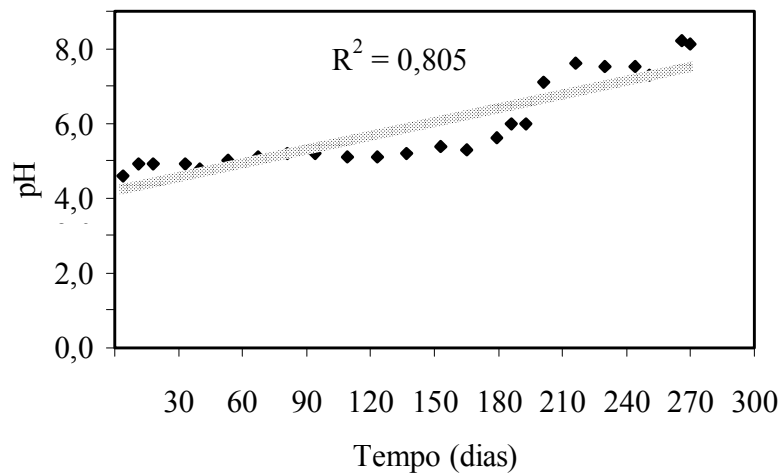

Figura 2. Variação do pH durante o período de monitoração do reator

Analisando-se o inicio do processo, correspondente à solubilização do material orgânico, o líquido percolado produzido continha espécies químicas com características ácidas, sendo que até os 170 dias de monitoração o valor do pH se encontrava em torno de 5,5. Somente aos 200 dias o líquido percolado adquiriu características de neutralidade. Este valor de $\mathrm{pH}$ funciona como um dos elementos indicadores de avaliação do desempenho do processo.

Leite (1997) tratando a fração orgânica putrescível de resíduos sólidos urbanos mais lodo de esgoto industrial, constatou que o valor do $\mathrm{pH}$ nos líquidos percolados tornouse favorável ao processo de bioestabilização anaeróbia somente aos 180 dias de monitoração. Neste período, o valor do $\mathrm{pH}$ estava em torno de 7,0, com a razão ácidos voláteis/alcalinidade total de aproximadamente 1,0 , demonstrando a presença do equilíbrio nas diferentes vias metabólicas.

Borzaconi \& Lopéz (1997) constataram que a bioestabilização de resíduos sólidos orgânicos produziu percolado com valores de $\mathrm{pH}$ em torno de 4,0 nos primeiros 175 dias de monitoração do sistema experimental. Sempre associados aos valores de $\mathrm{pH}$, estão os ácidos voláteis e a alcalinidade total. 
Os ácidos voláteis advêm da solubilização do material particulado e passam a ser substratos ou material tóxico para determinadas espécies bacterianas responsáveis pela bioestabilização do material orgânico. Segundo Kroeker (1979) os ácidos voláteis são tóxicos para as bactérias metanogênicas a concentração em torno de $2000 \mathrm{mgH}_{\mathrm{AC}} \mathrm{L}^{-1}$

A alcalinidade total é função da alcalinidade devido a bicarbonato e a ácidos voláteis. No caso do percolado e no início do processo de bioestabilização, os resíduos orgânicos produzem percolado com baixa alcalinidade a bicarbonato e elevada alcalinidade, devido a ácidos voláteis. À proporção que o processo entra na fase de equilíbrio dinâmico, a alcalinidade a bicarbonato passa a ser mais representativa quantitativamente. A quantificação da alcalinidade total é determinada pela Eq. (1).

$$
\mathrm{AT}=\mathrm{AB}+0,70 \mathrm{AV}
$$

em que:

$$
\begin{aligned}
& \text { AT - Alcalinidade total }\left(\mathrm{mgCaCO}_{3} \mathrm{~L}^{-1}\right) \\
& \mathrm{AB} \text { - Alcalinidade bicarbonato }\left(\mathrm{mgCaCO}_{3} \mathrm{~L}^{-1}\right) \\
& \mathrm{AV} \text { - Ácidos voláteis }\left(\mathrm{mgH}_{\mathrm{AC}} \mathrm{L}^{-1}\right)
\end{aligned}
$$

Na Figura 3 apresenta-se a variação da concentração da alcalinidade total e dos ácidos voláteis dos líquidos percolados advindos do processo de bioestabilização anaeróbia da matéria orgânica, durante 270 dias.

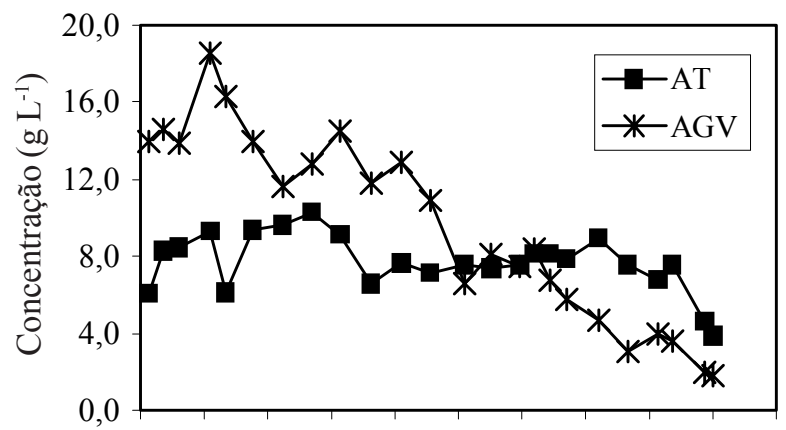

$30 \quad 60 \quad 90 \quad 120 \quad 150 \quad 180210240270300$

Tempo (dias)

Figura 3. Variação da concentração da alcalinidade total e dos ácidos voláteis

Aos 33 dias de monitoramento o percolado apresentava concentrações de ácidos voláteis e de alcalinidade total de $18,6 \mathrm{~g} \mathrm{H}_{\mathrm{AC}} \mathrm{L}^{-1} \mathrm{e} 9,3 \mathrm{~g} \mathrm{CaCO}_{3} \mathrm{~L}^{-1}$, respectivamente, estabelecendo uma relação AV/AT de 2,0, ou seja, uma concentração elevada de ácidos voláteis. Esses dados demonstram que não existe ainda uma forte relação simbiótica das diversas espécies de microrganismos presentes no sistema. Após 200 dias de monitoração, o processo de bioestabilização fornece agente tamponante ao sistema, haja vista a relação AV/AT se encontrar em torno de 0,7 , o que representa um crescimento bastante representativo da AT e, muito provavelmente, do percentual do gás metano no biogás produzido.

A DQO e o COT foram monitorados como parâmetros indicadores da transformação (bioestabilização) da matéria orgânica. Na Figura 4 apresentam-se as curvas de decaimento da concentração da massa de DQO e COT durante o período de monitoração.

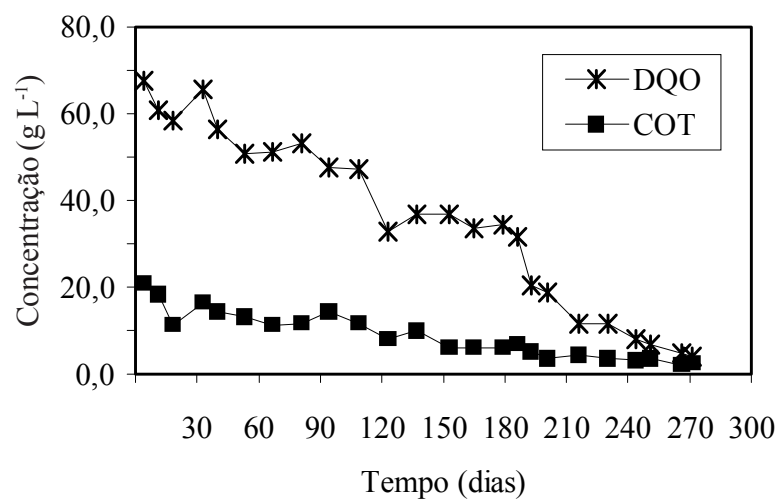

Figura 4. Perfil do decaimento da concentração da massa de demanda química de oxigênio (DQO) e COT

Monitorando-se os reatores anaeróbios de batelada, alimentados com fração orgânica putrescível dos resíduos sólidos urbanos, a massa de DQO afluente pode ser eliminada do reator pelos líquidos percolados que, dependendo do sistema de monitoração, pode-se perder uma fração bastante significativa de massa de DQO, uma outra fração é convertida em biogás, além da fração de DQO residual, isto é, a massa de DQO que fica retida na massa de resíduo parcialmente bioestabilizada. De maneira geral, espera-se que da massa total de DQO afluente, um percentual em torno de $80 \%$ seja transformado em biogás, em um período de tempo não superior a 300 dias. Uma das alternativas tecnológicas empregadas, para aproveitamento da massa de DQO eliminada no líquido percolado, é a recirculação no próprio sistema, alternativa que apresenta o inconveniente de, quando do início do processo de bioestabilização, o percolado apresentar características ácidas, exigindo correção do $\mathrm{pH}$. Portanto, inicialmente o percolado deverá ser submetido a um processo biológico de tratamento, onde ocorre redução de parte da carga orgânica e conseqüente elevação do $\mathrm{pH}$. Quando o $\mathrm{pH}$ atingir valores acima de 6 unidades, poderá ser recirculado sem maiores problemas.

Neste trabalho foi eliminada, através dos líquidos percolados, uma quantidade bastante representativa de massa de DQO, principalmente nos primeiros dias de monitoração. Observa-se, na Figura 4, a redução da concentração de DQO e COT, ao longo do período de monitoração do reator. A concentração máxima de DQO atingiu o maior pico nos primeiros dias de monitoração, isto é, nos quatro primeiros dias, cuja concentração média de DQO foi de $65,5 \mathrm{~g} \mathrm{~L}^{-1}$, tendo este mesmo fenômeno acontecido com a concentração COT. Supostamente, o fenômeno acontecido neste trabalho pode estar associado a forte solubilização do material menos particulado ao carreamento do material para a base inferior do reator, onde é acumulado e posteriormente descarregado. Mesmo tendo sido liberada uma parcela bastante significativa de massa de DQO no percolado, da massa de DQO retida no interior do reator a fração transformada em biogás produziu uma taxa de gás $\mathrm{CH}_{4}$ de aproximadamente $0,25 \mathrm{~N} \mathrm{~m}^{3} \mathrm{CH}_{4} \mathrm{~kg}^{-1}$ DQO 
No processo de bioestabilização anaeróbia de resíduos sólidos orgânicos são necessários, além de fonte de carbono, elementos nutricionais, como nitrogênio, fósforo e potássio. Quando se trabalha com resíduos sólidos orgânicos que apresentam desequilibradas relações $\mathrm{C}: \mathrm{N}: \mathrm{P}$, procede-se à introdução de determinados resíduos que possam equilibrar tal relação. Na Figura 5 apresentam-se as variações das concentrações de NTK, $\mathrm{N}_{-} \mathrm{NH}_{4}^{+}$e PT (fósforo total) dos líquidos percolados.

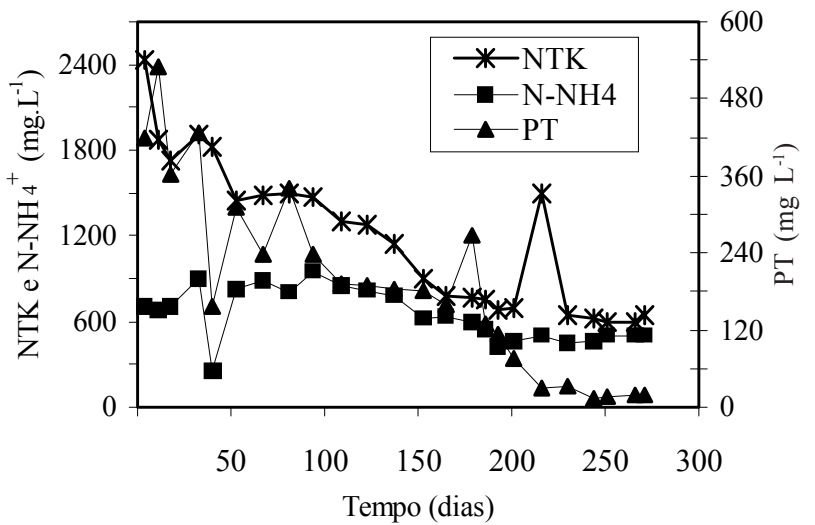

Figura 5. Perfís das concentrações de NTK, N-NH ${ }_{4}^{+}$e PT dos líquidos percolados

A concentração de NTK no percolado foi mais acentuada no início da monitoração, decrescendo gradativamente chegando, no final do período de monitoramento, a valores em torno de $0,5 \mathrm{gN} \mathrm{L}^{-1}$. A tendência da concentração de NTK foi também estabelecida para $\mathrm{N}-\mathrm{NH}_{4}^{+}$com similar grau de magnitude, enquanto o fósforo total foi solubilizado e lixiviado com maior intensidade no início da monitoração. À proporção que ocorria o equilíbrio do processo de bioestabilização anaeróbia da matéria orgânica, conseqüentemente era reduzida a concentração de fósforo total no percolado, atingindo valores de $10 \mathrm{mg} \mathrm{L}^{-1}$ aos 240 dias, conforme mostrado na Figura 5. A redução da concentração do material carbonáceo e dos nutrientes nos líquidos percolados, apresentou, no geral, comportamento semelhante.

$\mathrm{O}$ volume acumulado de biogás produzido é apresentado na Figura 6.

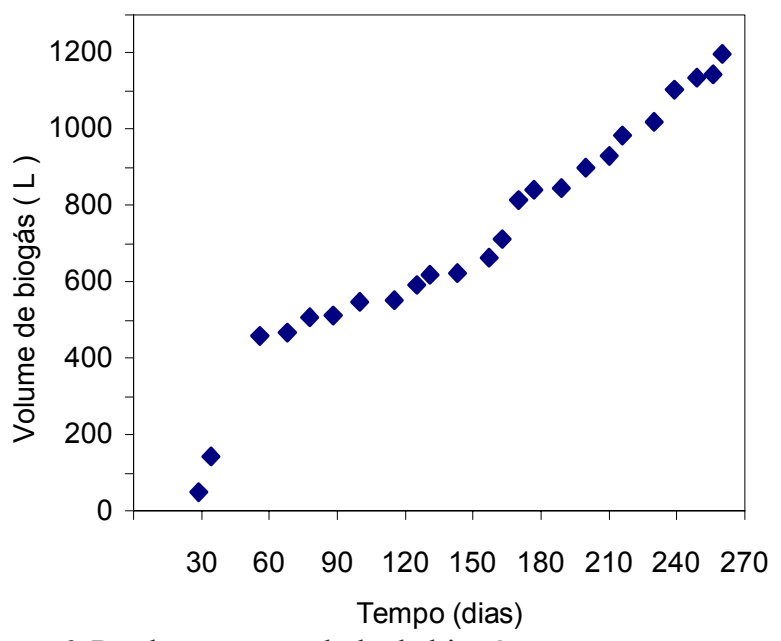

Figura 6. Produção acumulada de biogás
Para trabalhos desta natureza salienta-se que, quanto maior for o potencial energético dos resíduos sólidos orgânicos por volume de reator, mais viável economicamente se torna a alternativa tecnológica desenvolvida. Portanto, faz-se necessário que sejam estabelecidos mecanismos de bioestabilização de pelo menos $80 \%$ da massa de DQO alimentada ao sistema em um período de tempo de aproximadamente 200 dias. Neste trabalho, o biogás produzido continha em média $60 \%$ (percentagem em volume) de gás metano, podendo ser utilizado para queima direta ou indireta.

\section{CONCLUSÕES}

1. O tratamento anaeróbio de resíduos sólidos orgânicos, com aproveitamento do biogás, pode tornar-se uma alternativa tecnológica de relação satisfatória ao custo/beneficio.

2. Pode contribuir para minimizar os impactos ambientais causados pelos lixões, favorecendo a redução da poluição do solo, da água e do ar.

3. Processará mais da metade dos resíduos sólidos urbanos produzidos, quando o município disponibilizar pelo menos a coleta diferenciada dos resíduos.

4. Em sua totalidade, o processo é de fácil instalação e monitoração.

\section{AGRADECIMENTOS}

Os autores deste trabalho agradecem à FINEP/PROSAB, pela concessão dos recursos de custeio e capital para realização da pesquisa, e ao CNPq, pela concessão de bolsas de IC, AT e DTI.

\section{LITERATURA CITADA}

APHA, AWWA, WPCF, Standard methods for examination of water and wastewater. 18. ed. Washington, 1995, 1134p.

Barlaz, M.A.; Ham, R.K. Mass balance analysis of anaerobically decomposed refuse. Journal of Environmental Engineering, London, v.115, 1989, p.1088-1101.

Borzacconi. I.; Lopéz, I. Hydrolysis constant and VFA inibition in acidogenic phase of MSW anaerobic degradation. Water Science Technology, London, v.36, n.6/7, 1997, p.479484.

IPT. Instituto de Pesquisas Tecnológicas. Lixo municipal: Manual de gerenciamento integrado, IPT/CEMPRE, $2^{2}$ Edição Revista e Ampliada, São Paulo, 2000. 370p.

Kroeker, E.J. Anaerobic treatment process stabilty. Journal WPCF, London, v.51, n.4, 1979, 718p.

Leite, V.D. Processo de tratamento anaeróbio de resíduos sólidos urbanos inoculados com lodo industrial. São Carlos: EESC/USP, 1997. Tese Doutorado

Pavlostathis, S.G. Preliminary conversion mechanisms in anaerobic digestion of biological sludges. Journal of the Enviromental Engineering, London, v.114, n.3, 1998. 125p.

Tchobanoglous, G.; Theisen, H; Eliassen, R. Solid Wastes: Engineering principle and management issues. New York: McGraw-Hill Book Company, 1993. 621p.

van Haandel, A.; Lettinga, G. Tratamento anaeróbio de esgotos. Um manual para regiões de clima quente. Campina Grande: UFPB, 1994. 208p. 